\title{
Objetivos gerais de um programa de desenvolvimento profissional docente
}

\section{Broad objectives in a professional development program}

\author{
Anne Louise Scarinci ${ }^{1}$ · Jesuína Lopes de Almeida Pacca ${ }^{1}$
}

\begin{abstract}
Resumo: O trabalho analisa um programa de desenvolvimento profissional docente sob o enfoque da atuação do formador. Investigamos como este desenvolveu três objetivos que, em um diálogo entre dados e literatura, consideramos como transversais para a formação continuada docente: a reflexão sobre a prática, o desenvolvimento da autonomia e a compreensão de uma concepção de ensino. A análise traz trechos dos diálogos no programa de formação em que tais saberes estão sendo trabalhados, de modo a produzir resultados acerca do modus operandi do formador, focalizando suas atitudes, sua sequência de ações e as ênfases que atribui ao processo formativo. Em nossos resultados, caracterizamos habilidades que foram favoráveis para o desenvolvimento dos objetivos da formação e saberes que permitiram o estabelecimento de uma interação produtiva. Dentre as conclusões, apontamos como fundamental o profundo respeito aos participantes do programa de formação, assumindo como pressupostos a competência, o compromisso e a ética daqueles profissionais.
\end{abstract}

Palavras-chave: Formação de professores. Construtivismo. Autonomia docente. Ação.

\begin{abstract}
The paper analyses a teacher professional development program focusing the teachers' educator performance. We've investigated how the educator developed three objectives that were transversal in teachers' education: the reflection about practice, the development of autonomy and the comprehension of a teaching-learning conception. The analysis includes extracts of dialogues in the program, in which such knowledge is being worked, so as to produce results that account for the modus operandi of the educator, identifying his attitudes, his sequence of actions and the emphases he attributes in the educative process. In our results, we characterized the abilities that were favorable to the development of the education objectives and knowledge that allowed the establishment of a productive interaction. Amongst our conclusions, we emphasize the profound respect towards the professionals who participated in the program, by taking as premises the competence, commitment and ethics of those professionals.
\end{abstract}

Keywords: Teacher education. Constructivism. Teacher autonomy. Action.

\footnotetext{
${ }^{1}$ Universidade de São Paulo (USP), Instituto de Física, São Paulo, SP, Brasil. E-mail: <anne@if.usp.br>.
} 


\section{Objetivos transversais para a formação docente}

Professores em geral se ressentem da condição de solidão a que a prática profissional os relega e a busca por programas de formação continuada representa, muitas vezes, um reflexo desse sentimento de desamparo e desejo de formar parcerias que o ajudem a dar conta do fazer profissional cotidiano. Eles têm problemas para discutir e que precisam resolver, como desinteresse dos alunos, baixa aprendizagem de algum conteúdo, dificuldades de manutenção de disciplina, etc. e esperam que o aprimoramento profissional vá ajuda-los a encaminhar soluções para tais problemas.

Por outro lado, a maior parte das ações em formação continuada para docentes prevê um formador especialista em uma área específica, que monta previamente um programa de ensino e a ação de formação propriamente dita é a comunicação aos professores daqueles objetivos escolhidos pelo formador. Do ponto de vista do professor, ele termina tais cursos e vai para a sala de aula com um novo problema: o de "aplicar" aquele novo conhecimento em sua prática profissional. Em geral, os cursos não se ocupam de conectar os conteúdos e objetivos propostos com problemas que os professores já têm (ou estes não entendem aqueles conteúdos como relacionados a respostas para seus problemas).

Quando um programa dá voz ao professor, ele é capaz de produzir situações-problema muito relevantes e que certamente renderiam discussões e aprendizagens produtivas. Por exemplo, o professor JOS dera uma atividade avaliativa aos seus alunos e relata, no programa de formação, os resultados obtidos, já incluindo uma reflexão sobre sua atuação nas aulas anteriores a essa avaliação:

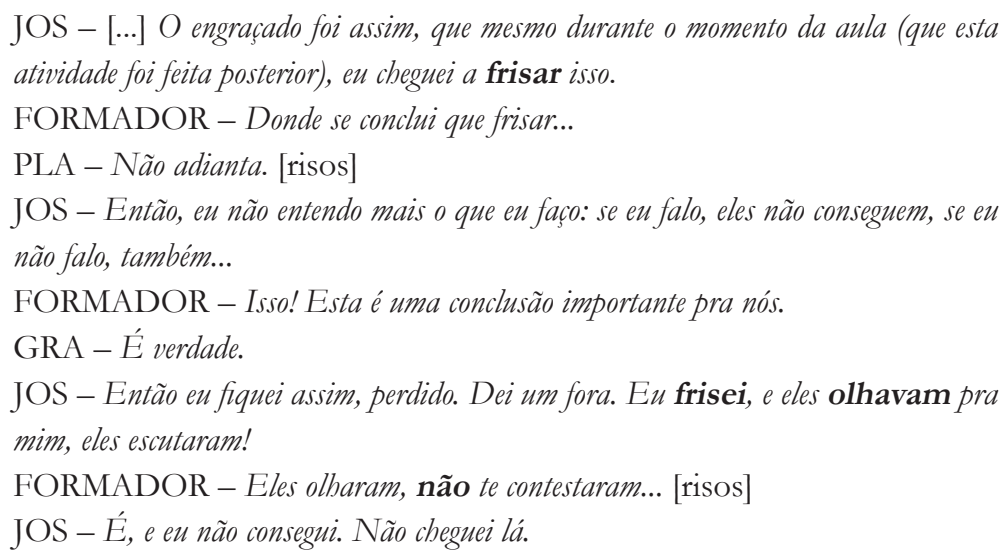

Com efeito, essa é uma constatação de vários autores que se debruçaram sobre o problema da formação docente: os programas de formação deveriam partir da prática do professor (ALARCÃO, 1996; LYONS, 2006; PIMENTA; GHEDIN, 2002; VILLANI; PACCA, 1996, dentre outros). Contudo, isso exige do formador planejar o programa de uma forma bastante diversa do usual, pois o planejamento do ensino e a escolha dos conteúdos seriam mais flexíveis (de forma a acolher adequadamente as necessidades que se expressam), porém os objetivos 
devem ser claros a fim de produzir um direcionamento às interações que chegue a um aprendizado real, e que o professor reconheça como relevante para a solução dos problemas. Que objetivos seriam convenientes?

Encontramos na literatura específica do tema Formação Docente uma base teórica ampla e aprofundada sobre que elementos devem integrar a formação do professor (CONTRERAS, 2002; NÓVOA, 1995; PERRENOUD, 1993, SOUZA, 2004; VIEIRA, 1994, dentre outros). Essa mesma base nos fornece orientações gerais de como deve acontecer essa formação - fundamentadas, naturalmente, no que se entende por educação escolar para a nossa sociedade e pela função do professor nesse contexto.

Cursos pós-universitários para professores de física geralmente explicitam os objetivos específicos de ensino, com conteúdos a serem aprendidos (e.g. astronomia ou física moderna) ou estratégias tais como o uso de atividades experimentais. Subliminarmente a esses conteúdos, entretanto, formadores também muitas vezes intencionam trabalhar objetivos mais gerais e relacionados ao fortalecimento da profissionalidade docente. Em um passeio pela literatura recente sobre o tema, reunimos três objetivos que se configuram como muito oportunos, porque relacionados às necessidades que os professores expressam, e ao mesmo tempo coerentes com os anseios sociais de uma formação ampla dos alunos na Escola Básica: o desenvolvimento da capacidade reflexiva e de investigação da prática, a compreensão de uma concepção de ensino e a promoção da autonomia profissional.

\section{A atitude reflexiva}

A reflexão sobre a prática proporciona ao professor recuperar a capacidade de descrição e análise das suas ações rotineiras, com base nos seus critérios implícitos (STENHOUSE, 1984). Essa é uma recomendação contundente para a formação docente: deve possibilitar espaço para que o professor possa, mediado pelos pares e pelo referencial teórico em pauta, refletir sobre sua prática.

A reflexão, especialmente em relação aos objetivos das ações educativas, é bastante apropriada porque, como defende Schön (2000), o ensino não é uma simples aplicação técnica de um conhecimento, do que decorre que não há uma resposta nos livros para vários dos problemas enfrentados na sala de aula.

Não é suficiente que a reflexão e a investigação da prática se deem circunscritas às práticas individuais e ao contexto recortado da sala de aula, pois apenas a consideração e crítica do contexto social mais amplo, condicionante da prática profissional, proporcionam maior compreensão da prática e de seu potencial transformador (PIMENTA, 2002). Um dos pontos enfatizados por Zeichner (1992), a partir dessa análise, é que a prática reflexiva se realize em coletivo.

O pensamento reflexivo sistemático, no sentido de fazer da prática docente um campo de reflexão teórica como estruturadora da ação, é uma capacidade a ser desenvolvida, ou seja, que não desabrocha espontaneamente (ALARCÃO, 1996). Justifica-se, por conseguinte, que a reflexão se coloque como um objetivo mais amplo de um programa de desenvolvimento profissional docente. 


\section{Compreensão de uma concepção de ensino}

Professores em serviço já detêm um conjunto de saberes que, minimamente, funcionam no sentido de prover sua sobrevivência na profissão. Dentre esses saberes estão formas de explicar o conteúdo, de manter a atenção da classe, de motivar os alunos, de montar uma avaliação escrita, responder perguntas, etc. Cada uma dessas competências não se manifesta isoladamente, mas faz parte de um todo, de uma estrutura de ação que apresenta certa coerência interna, em termos de relação com uma concepção de ensino e aprendizagem (embora esta concepção nem sempre esteja em nível consciente).

Pode-se argumentar que as práticas de um professor raramente seriam todas absolutamente coerentes com uma determinada concepção de ensino e aprendizagem; contudo, uma vez que esse professor é invariavelmente participante de um determinado paradigma, suas ações estarão essencialmente insertas nele. Agir consistentemente dentro de uma visão de mundo simplifica o planejamento e a interpretação da realidade, porque cada passo partilha de um mesmo contexto implícito. Deste modo, a previsibilidade sobre as interações com os alunos é grande e um plano de curso consegue efetivamente servir de guia durante a realização das aulas. Além disso, a capacidade de improvisação do professor é alta. Ele se sente confortável na aula, porque sabe o que faz̧er quando surgem situações inesperadas ou dificuldades de aprendizado/ comportamento que não haviam sido previstas (SCARINCI; PACCA, 2013).

Programas de formação continuada procuram ensinar determinadas práticas ao professor, desejando que ele opere uma modificação de sua atuação e de seu plano de ensino, conforme os conhecimentos aprendidos. O empreendimento parece simples apenas sob um olhar muito superficial, pois frequentemente esta mudança esperada se embasa em concepções de ensino, de aprendizagem e de ciência, diferentes daquela que o professor possui. Assim, a operacionalização da proposta do programa envolve uma alteração de toda a estrutura de pensamento e ação, e não somente de um subconjunto de práticas, por exemplo, de inserção de atividades experimentais, introdução de problemas abertos ou explicitação das ideias prévias dos alunos.

Quando o aluno tem uma pré-concepção, deixo passar ou dou uma explicação? O que eu faço depois que ele falou a pré-concepção? Porque se eu deixo passar, ele vai ficar com a impressão de que está certo, né, porque eu não falei nada, 'se a professora não falou nada é porque está certo'... (SCARINCI, 2010, p. 19).

No exemplo acima, a professora estava aprendendo a realizar atividades experimentais investigativas. Mas, obviamente, tais atividades produziriam uma mudança fundamental em toda a sua atuação posterior, inclusive em como conduzir explicações, aulas expositivas, aulas de exercícios, etc. Um dos passos fundamentais, portanto, é que o professor compreenda mais profundamente a teoria que embasa os conhecimentos que estão sendo veiculados e saiba relacionar essa teoria com uma atuação docente consistente.

\section{A promoção da autonomia profissional}

A compreensão radical dos fundamentos de suas ações docentes é um dos elementos que favorecem a promoção da competência profissional e, de forma mais ampla, da autonomia docente, e argumentamos que esta configura-se também como um objetivo desejável aos programas de formação. O conceito de autonomia foi abordado por Contreras (2002) e evidenciado 
como uma medida de resgate da profissionalização. O autor, contudo, não a considera como sinônimo de liberdade: procedendo a uma análise pormenorizada do conceito e comparando-o à autonomia em outras profissões, o autor conclui que a autonomia deve vir vinculada a propósitos claros em termos da função social do trabalho docente, sob risco de desembocar em um isolamento e individualismo prejudiciais à prática educativa, ou ainda de se tornar um slogan usado pelo sistema para cobrar do professor colaboração com os propósitos e eventuais políticas reacionárias do Estado.

A partir disso, Contreras (2002) reconduz o olhar sobre a autonomia profissional ao âmbito da responsabilidade e do compromisso inalienáveis que o professor tem para com assuntos concernentes à sua sala de aula. Sob esse foco, a autonomia é entendida como uma capacidade de decidir imprescindível ao trabalho do professor, visto que é a ele, em última análise, que se confia o ofício de educar, e é somente ele quem pode assumir o juízo diante das variadas situações que surgem na sala de aula e no contato direto com os alunos.

Ressalvando que a ação autônoma não deve ser confundida com aquela que exclui a comunidade das decisões educativas que a afetam, o autor edifica a autonomia sobre um tripé de dimensões da profissionalidade que considera qualidades necessárias ao trabalho de ensinar: a obrigação moral, o compromisso com a comunidade e a competência profissional.

É dentro de um compromisso ético que se justifica, portanto, a autonomia, enquanto qualidade que permite o cumprimento da responsabilidade pelo educar. A sustentação desse valor requer não somente o seu reconhecimento legal, mas também a presença de capacidades intelectuais e morais. E essas competências são impulsionadas pela vontade de bem ensinar, e desenvolvidas através do reconhecimento da capacidade da ação reflexiva, bem como da elaboração de conhecimento profissional.

Elegemos, destarte, esses três objetivos mais gerais para a formação continuada de professores, subsidiados pela literatura em formação docente identificada anteriormente. São objetivos que conseguem estar circunscritos pelo que se entende por desenvolvimento profissional docente (NÓVOA, 1995), no sentido de valorizar dimensões coletivas que colaborem para a emancipação profissional e consolidação de uma autonomia para a produção de saberes docentes. O nosso interesse neste trabalho será de investigar como ações efetivas na promoção dessas competências foram engendradas, em um contexto específico.

\section{A investigação: contexto e metodologia}

Quisemos estudar como esses objetivos da formação docente se concretizariam em um programa de formação de professores de ciências. Acompanhamos um programa em modalidade formação continuada, voltado para professores de física, que funcionou na cidade de São Paulo. Observamos as ações do formador, que poderiam estar conectadas com tais objetivos. A escolha do programa deveu-se aos resultados alcançados em termos do desenvolvimento profissional docente, conforme relatado em Scarinci (2006).

A comunidade de formação constituiu-se dentro de um programa Fapesp-Escola Pública. O formador era um docente universitário e era auxiliado por 2 a 3 alunos de pós-graduação em ensino de ciências com experiência docente. Os professores eram em número de 10 a 12 (nos dois anos em que acompanhamos o programa) e eram professores típicos da escola 
pública: tinham formações iniciais variadas (física, matemática, biologia, ciências da natureza), não estavam envolvidos em programas de pós-graduação strictu sensu ou ligados de outra forma a universidades, e tinham como condição para participação no programa ministrar aulas de física em escolas públicas, dispor de tempo para as reuniões semanais (6 horas presenciais e outras 14 horas de trabalho individual) e ministrar em ao menos uma turma aulas do tema científico em foco pelo programa naquele ano (2008 - eletromagnetismo; 2009 - óptica).

O programa acontecia nos moldes de um grupo de pesquisa-ação (portanto sem um início ou término pré-determinados) de forma que os professores participantes poderiam estar no grupo há 5 ou 6 anos ou serem iniciantes. O programa fornecia uma bolsa para os professores (de valor equivalente ao de uma iniciação científica), porém não fornecia uma certificação válida para propósitos de progressão funcional.

A pesquisa foi realizada através de observação participante, com inserção prolongada do observador na comunidade de formação, anotações de campo e áudio-gravação das reuniões de formação, além da análise documental (de textos produzidos pelos participantes) e de conversas com alguns informantes selecionados. O nosso sujeito de pesquisa foi o formador do programa.

A análise dos dados obtidos pautou-se na metodologia de análise do discurso, tendo como foco central a análise e relação entre a linguagem e seu contexto de produção. Aqui, a referência adotada tem raízes em Pêcheux e é assim compreendida por Minayo (2010, p. 319, grifo do autor): "as técnicas de análise de discurso pretendem inferir, a partir dos efeitos de superfície (a linguagem e sua organização), uma estrutura profunda: os processos de sua produção". Entendemos que a situação em estudo está atestada nos depoimentos dos sujeitos de pesquisa, sendo que o que cabe ao pesquisador é compreender o seu processo produtivo. Consideramos que o discurso tanto dialoga com outros discursos, quanto se produz no interior de grupos que determinam quem fala, como, quando e o que é falado.

A dinâmica das interações do grupo nos permitiu subdividir as reuniões em episódios, cujo início se dava com a apresentação de uma questão-problema (geralmente por um professor participante). O desenvolvimento do episódio contava com a participação de vários membros do grupo e o desfecho usualmente ocorria com uma colocação mais longa do formador.

Nossa análise se pautou principalmente nas transcrições integrais dos episódios de formação, que foram inicialmente classificados segundo o objetivo específico de ensino atingido (nessa etapa, foram analisados cerca de 40 episódios). Em um segundo momento, fizemos nova aproximação aos dados, em função de objetivos mais gerais, e que estariam transversais a todos os episódios, apoiando-nos, para a busca de tais marcas, na literatura sobre a formação docente, conforme explanada anteriormente. Dessa forma, esta análise foi fruto dessa segunda aproximação aos dados, em um movimento de várias idas e vindas entre os dados empíricos e os referenciais teóricos.

\section{Análise}

\section{A reflexão sobre a prática}

No programa analisado, constatamos que atitude reflexiva foi promovida partir da estratégia utilizada pelo formador para o início de todas as reuniões - que era pedir a um professor 
que relatasse suas aulas, com foco nos alunos e nas interações entre eles e com o professor, e entre eles e o conteúdo. A capacidade de reflexão sobre a prática foi, portanto, desenvolvida a partir de um ponto de partida que era o motor de todas as ações do programa: a própria prática docente. A partir do relato de um professor, o formador fazia perguntas ou observações, chamando a atenção a determinados pontos, e que incentivavam o início de uma reflexão.

No episódio ilustrado a seguir, a professora PLA conta uma aula pertencente ao conteúdo de magnetismo, em que fizera uma atividade com ímãs. O objetivo imediato era que os alunos descobrissem quais seriam os polos sul e norte de um ímã. PLA relatou que distribuíra dois ímãs a cada grupo, e que a conclusão a que os alunos chegaram fora de que "sul com sul repele e norte com norte atrai". PLA se mostra frustrada com essa situação. Os demais professores (representados nas transcrições por conjuntos de três letras) e o formador (representado por F) buscam auxiliá-la a compreender o fracasso da atividade.

PLA - Na verdade, eu estava ansiosa que eles falassem da bússola. Eles não falaram! F - Pois é, eles não falaram. Eles não falaram, então você foi lá e... e disse, "é isso que eu quero que vocês falem. Mesmo que vocês não entendam nada, é isso que eu quero que vocês falem." [risos]

VIC - Eu ainda não consegui entender o que está acontecendo na aula da PLA - Você deu os imãs pra eles, pra dizerem qual era o Norte e o Sul. Mas só com os ímãs eles teriam condiçôes?

PLA - Claro que não, eu queria que eles falassem que não dava. [...]

CLO - Mas não tinha bússola [!].

PLA - Tinha bússola! Só que estava na [minha] mesa. Eu não falei da bússola. E eles tinham feito a bússola no semestre passado.

VIC - Aaabhb bom! Ah, entendi, agora entendi. Você queria que eles fizessem a ligação [da atividade dos ímãs] com a [atividade anterior da] bússola. [...]

$\mathrm{F}-\mathrm{E}$ ai você não ficou triste?

PLA - Fiquei. Fiquei meio decepcionada.

F - Mas você entendeu a raiz da tua decepção? [...] Então você vê? Vocês veem como é fácil a gente escorregar e se esquecer de olhar para o aluno? E de pensar com a cabeça dele? A gente quer contradizer para substituir o erro dele pelo acerto. [...] Então, o que ele estápensando, a justificativa que ele é capaz de dar pra aquela resposta que ele está oferecendo para o problema é importante pra gente. Porque é ai que eu vou discutir. É ai que eu vou procurar "contradizer", com fatos, com outras informaçôes. Mas eu tenho que estar sempre atento para saber o que o sujeito está pensando e que torna aquela resposta possivel pra ele.

A reflexão sobre a prática, que proporcionou as situações de ensino do programa, foi realizada pelo recurso do diálogo, a partir de um relato de aula. Então o diálogo entre um professor que relata sua prática e o formador, com a colaboração dos demais participantes, foi a célula básica de funcionamento do programa.

Essa reflexão sobre a prática não foi realizada individualmente, mas em coletivo. $\mathrm{O}$ professor se sentia seguro em relatar suas aulas (mesmo que ele as qualificasse como desastrosas) porque tinha uma equipe de colaboradores - que eram seus pares, então também tinham 
experiência docente, passaram por situações semelhantes e estavam ali para se desenvolver juntos - e também porque nessa equipe ele via um membro mais experiente e que estava disposto a auxiliá-lo, que não pecaria pela superficialidade nem pelo julgamento precoce. Ou seja, o programa criou um ambiente de compromisso entre os participantes, com responsabilidade pela melhora conjunta do processo educativo de cada um.

Embora o caminho percorrido pelos participantes em um episódio de formação seja dependente do tipo de episódio tratado (tivemos episódios com foco maior na condução da aprendizagem em sala de aula, como o ilustrado acima, mas houve outros com foco no conhecimento de física, ou no planejamento do ensino, ou no processo de avaliação, na organização escolar etc.), conseguimos identificar uma forma geral para a evolução do diálogo, com três fases:

Fase introdutória: o professor relata a sua aula (ou seu problema) ao grupo. Nessa parte, são providas as informações contextuais básicas (como o número de alunos na classe ou o dia da semana em que a aula aconteceu), o que o professor fez e o que ele percebeu, ao menos inicialmente, do comportamento dos alunos. Essa também pode ser a fase da queixa, quando se trata de um tema relacionado a dificuldades disciplinares com alunos ou condições de trabalho inadequadas para o desenvolvimento da aula.

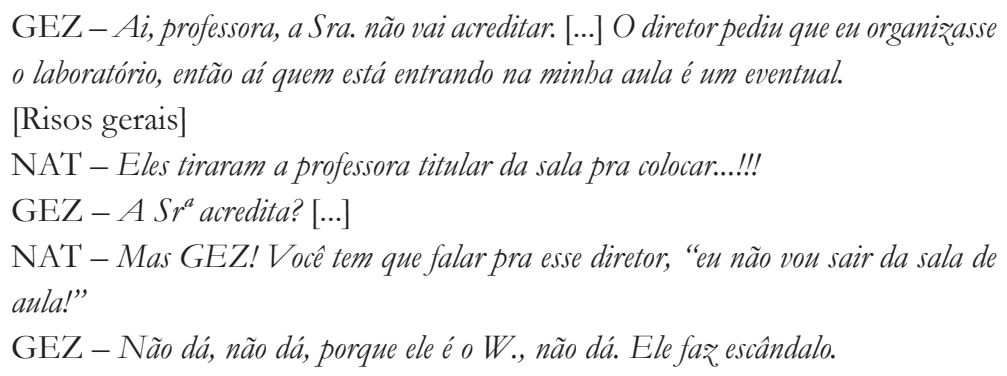

As intervenções do formador (e do grupo) nessa fase caracterizam-se por ouvir atentamente e fazer as perguntas necessárias para formar uma "paisagem mental" daquela situação relatada, com todos os detalhes que possam ser pertinentes.

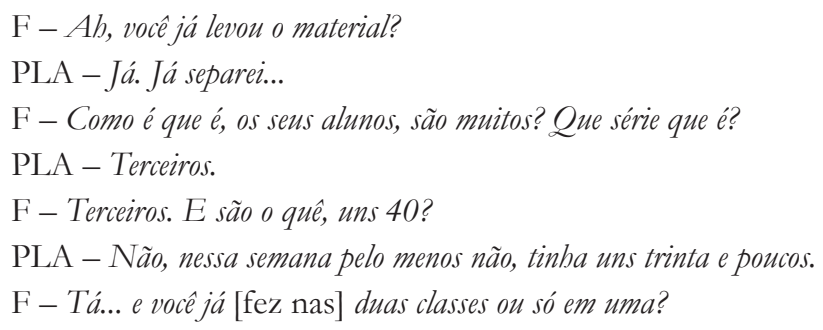

O formador ouve o professor atentamente. Da mesma forma que ele ouve, ele também está ensinando, pelo exemplo, que o professor deve ouvir o seu aluno. Os professores de fato percebem e aprendem com isso - como no depoimento abaixo, em que a professora HAF reflete sobre uma aula em que pedira aos alunos explicar o funcionamento da pilha: 
Por exemplo, eu notei o seguinte, que como eu tenho muito o bábito de - eles começam a falar, eu falo junto, sabe? Eu percebi isso. Eu teria que primeiro ouvir, eu acho que eu não tenho muito o hábito de ouvir; eu preciso ouvir, dar um tempo... [...] porque eles ficam meio agitados, vão querer falar e dai eu falo junto... E dai também eu perco o que eles estavam falando.

Fase exploratória ou interpretativa: Procuram-se os determinantes implícitos da situação vivida. Nota-se que nessa fase não há ainda a busca por soluções; o centro permanece no problema relatado. Frequentemente o professor fornece novos elementos contextuais, a partir de perguntas do formador ou de outros participantes; podem também entrar elementos teóricos de interpretação (a partir do maior conhecimento do formador), ou saberes experienciais (a partir de casos vividos por outros participantes).

PLA - Eu dei aula, mas não dei o que eu queria, porque eu tinha passado exercícios, eu passei as formulinhas, né. Fórmula da resistência... [...] então na outra aula eles queriam que corrigisse, que eu tinha marcado prova. Ai eu corrigi os exercícios e dei a prova, só de formulinhas. E eu marquei com eles

$\mathrm{F}-\mathrm{O}$ que quer dizer que você corrigiu exercícios?

PLA - Ab, eles têm dúvida, "ah, eu não consegui fazer esse", eu peguei exercícios de vestibular, assim.

$\mathrm{F}$ - Mas o que que é corrigir exercício?

PLA - Ab, é corrigir na lousa...

$\mathrm{F}$ - Não, "corrigir na lousa" não, corrigir é corrigir alguma coisa.

PLA - [...] Não, não é corrigir; é fazer. [!]

$\mathrm{F}-$ Pois é... Então...

PLA - Alguns, até perguntam, "ah, eu não consegui, eu estou travado aqui", aí...

F - Mas isso não se chama corrigir também. Não é? O que você fez̧, afinal de contas?

Descreve o que você fez.

O fechamento dessa fase acontece quando se compreende a dificuldade "real" do professor para lidar com aquele problema surgido, que geralmente se encaixa em:

- Dificuldade (do professor) com o conteúdo de física;

- Perda do foco no aluno;

- Incoerência da estratégia adotada com o objetivo desejado;

- Expectativas incoerentes com a realidade (os alunos e as condições de trabalho);

- Necessidade de replanejamento provocado por fatores externos.

Fase conclusiva: trata proativamente das possibilidades de ação do professor, dentro dos determinantes contextuais analisados nas fases anteriores. Essa fase retoma as colocações das fases anteriores do diálogo e encaminha uma ação concreta, relacionada ao planejamento do professor e ao conteúdo que quer ensinar.

F - Agora veja uma coisa, PLA. Olha, quando a gente põe uma coisa na lousa, a gente dá assim, um modelo, né...

PLA - É, ai não adianta nada, eles copiam... 
F - Não, não é que não adianta nada, adianta também. Não sei se adianta para o que você quer. [...] Então, mostrar os modelos, os protótipos e tal, também é considerado como uma atividade interessante. Mas será que a gente faz isso com consciência de que faz isso? Será que eu queria isso no planejamento ou não? Então essa que é a questão importante.

As ações mais frequentes, conforme análise transversal dos episódios, foram:

- Modificar o plano de ensino (incluir uma nova atividade para a próxima aula, modificar alguma já existente ou inverter a ordem, ou então compreender a mudança necessária no planejamento para a próximo ano);

- Compreender uma atitude a ser tomada (prestar mais atenção à dificuldade do aluno, analisar essa dificuldade, procurar os esquemas mentais subjacentes ao erro através de um diálogo mais efetivo com seu aluno);

- Relacionar o conteúdo de física (muitas vezes recém aprendido) com uma maneira de ensiná-lo (o que geralmente incorre também na modificação do plano de aulas e definição de atitudes);

- Assumir um posicionamento firme e fundamentado frente à situação e realizar a ação possível.

O formador assume a função de conduzir a reflexão do professor sobre sua prática docente, aproveitando adequadamente os relatos e depoimentos e mobilizando seus saberes e habilidades na interação com o professor. Algumas dessas habilidades podem ser assim descritas:

- A escuta qualificada - identificamos essa habilidade como a de ouvir o professor e, a partir do seu relato, compor mentalmente a cena relatada, incluindo todos os detalhes possíveis; compreender as ações, intenções e dificuldades relatadas. Ouvir as entrelinhas de um relato: compreender um depoimento do ponto de vista do seu referencial e também do referencial do professor. Abrir-se para o que o outro tem a dizer antes de pensar no que falar em retorno.

- A atitude não diretiva - é o cuidado com assunções precoces. Nas fases inicial e exploratória do diálogo, enquanto ainda se procurava o problema real e suas causas e determinantes, o formador se abstinha de fazer inferências sobre o que o professor fez, sobre como seus alunos reagiram ou sobre que intenções o professor teve com a aula que estava relatando. Ele buscava todas as informações, abrindo espaço para que o professor fizesse um depoimento o mais detalhado possível e lhe fazendo perguntas de cunho descritivo. Esses questionamentos contextuais muitas vezes já proporcionavam o início de uma análise reflexiva da situação vivida.

- A memória processual - o formador se lembrava dos detalhes contextuais no desenrolar do episódio, de modo a considerá-los para a fase conclusiva. Além disso, o formador também se lembrava do histórico do professor com aquela sua classe, quando, em uma reunião posterior, este tinha uma nova aula para relatar. $\mathrm{O}$ formador procurava conhecer o professor, seus saberes, sua personalidade, sua subjetividade.

- O foco - a objetividade; a habilidade de não se perder no pitoresco de um relato, ou de não permanecer em seus condicionantes externos, sobre os quais o encaminhamento independe de uma ação ou aprendizado do professor. É emblemático que muitas discussões tenham fechamento no olhar sobre o planejamento. Os professores sentiam que as discussões eram úteis porque terminavam em uma ação possível, que estava em seu poder e em seu rol de competências engendrar. 
Como diz Pimenta (2002), a reflexão, enquanto saber profissional do professor, é aprendida e não dada. O formador desse programa mobilizou uma estratégia de ensino - o diálogo a partir do relato da prática - que se mostrou eficiente para que essa reflexão fosse desenvolvida pelo grupo de professores participantes. A reflexão praticada oralmente nos momentos de formação seria depois refinada e sistematizada, por meio de tarefas escritas requeridas dos participantes.

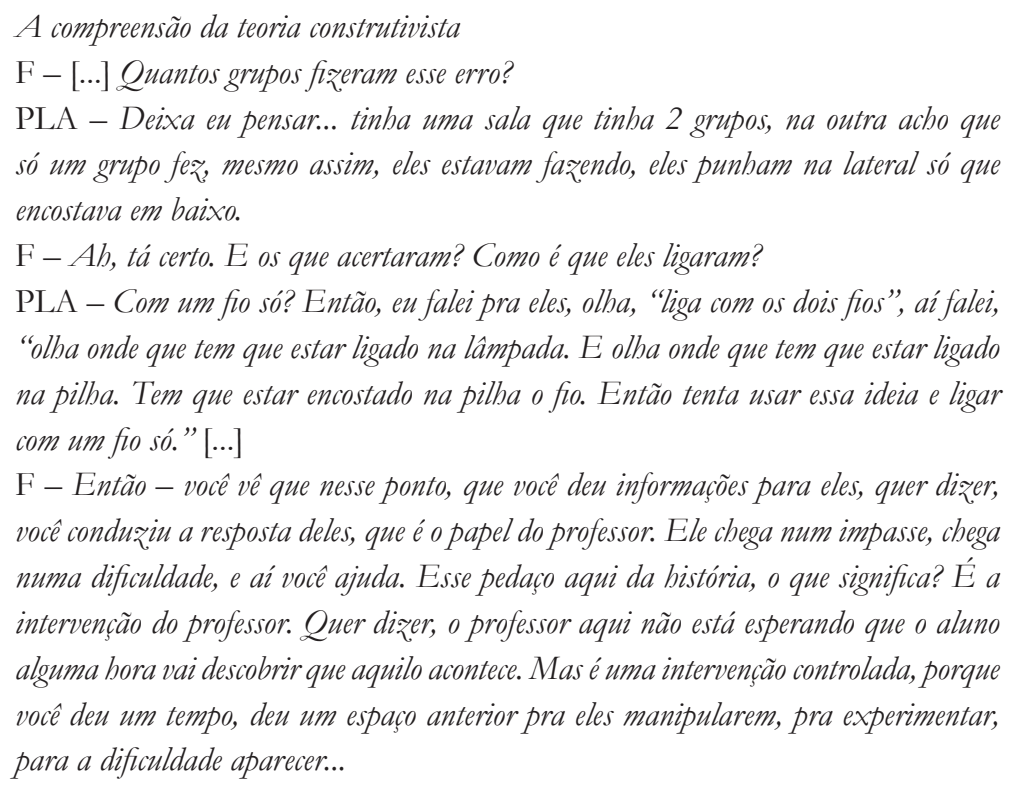

Os episódios de formação, em sua grande maioria, traziam ideias construtivistas (tais como dar espaço para o aluno pensar, ouvir o aluno, trabalhar com o erro como elemento integrante do aprendizado, conduzir as ações docentes a partir do feedback contínuo) embutidas no próprio diálogo sobre as aulas que o professor relatava que fez ou que pretendia fazer. No entanto, curiosamente o formador não discorria sobre autores ou pressupostos teóricos da linha epistemológica-pedagógica adotada no programa, embora tal visão epistemológica e pedagógica fosse um objetivo de ensino. Percebemos que o formador adotava ideias construtivistas, tanto na condução das reuniões como na interpretação dos depoimentos dos professores, contudo não "dava aulas teóricas". Como os professores se relacionavam com essa proposta?

Apresentamos a seguir um episódio dentre os poucos que trabalharam explicitamente com o referencial teórico, durante os dois anos em que acompanhamos o grupo. O episódio se inicia com perguntas do professor VIC, que está procurando interpretar a orientação geral do programa quanto a produzir as aulas de física partindo de situações concretas, experimentais, em vez das usuais aulas "normais", em que o conceito vem antes e a comprovação empírica o sucede.

VIC - Esse método que a gente está tendo, através da experiência, é o indutivo, e o outro [que eu fazia] é o dedutivo? A gente pode dizer isso ou não? 
F - Olha... A gente pode dizer isso, grosso modo, mas na verdade, dizer que é dedutivo quer dizer que na cabeca do aluno existe a teoria e dai ele pode extrair as outras coisas. VIC - Porque o que se tenta fazer normalmente é um método dedutivo, a gente tenta enfiar isso na cabeça dele/

$\mathrm{F}$ - A gente tenta usar o método dedutivo, só que ele não é uma possibilidade, porque o sujeito não construiu aquela teoria. O que nós estamos fazendo aqui é tentando levar o sujeito a construir a teoria. [...]

PLA - É, porque na verdade, quando a gente dedur, a gente está usando o método dedutivo pra gente, a gente está deduحindo. Mas o aluno não está dedurindo.

$\mathrm{F}$ - Por isso nós podemos até dizer que estamos usando o indutivo e o dedutivo em todos os momentos. Mas na verdade, o que vale, nós estamos usando o método construtivista. Quer dižer, o sujeito está construindo, e o concreto, pra ele, nesta fase de construção, é muito importante. Porque as concepções espontâneas que ele tem, todas vêm do concreto, todas vêm da vivência dele. [...] Quando o aluno fecha resultados, quando ele vem com uma ideia, a gente diz assim, puxa, ele construiu um pedaço da teoria, então dali ele pode usar o dedutivo. Ele pode tirar outras consequências.

VIC procura encaixar o trabalho desenvolvido no programa com uma linha teórica, com uma nomenclatura específica. O professor participante do programa, em certo momento, poderia fazer esse tipo de perguntas, e era atendido. Mas essa não era uma iniciativa que partiria do formador. O professor não era constantemente informado sobre o construtivismo, assim como não recebia orientações gerais sobre a ideia de professor-pesquisador, ou de reflexão sobre a prática ou ainda da construção da autonomia docente. Ele de fato era convidado a se engajar em ações, ele praticava esses conceitos, vivenciava-os, enquanto participava das atividades do programa.

Por que esse programa privilegiou situações de vivência? Por que explicações e abordagens mais "diretas" da teoria não aconteciam?

A explicação do formador a VIC, no episódio anteriormente transcrito, sobre a construção do conhecimento em física partindo da fenomenologia, é análoga à que nos foi explicada pela equipe de formação. Na lógica que quem já compreende a teoria construtivista, pode-se explaná-la e depois discorrer sobre sua aplicação a situações de ensino e à aprendizagem dos conceitos. Mas para quem aprende, uma explanação teórica anterior à vivência do sujeito ou à observação da aprendizagem segundo aqueles pressupostos, é muito complexa e pouco compreensível.

Maldaner (2006), observando o comportamento de professores em um programa de desenvolvimento profissional, percebeu que a cada vez que o formador explicava um conceito abstrato da pedagogia construtivista aos professores, estes esforçavam-se para fazer referência a aulas que davam, procurando relacioná-las com aquele conceito, na tentativa de compreendê-lo. Maldaner comenta que "A fala do professor acontece, geralmente, em patamar diferente do patamar de entendimento dos alunos. Isto também acontece, muitas vezes, nas falas dos professores universitários em relação aos entendimentos dos professores de outros níveis escolares" (MALDANER, 2006, p. 199).

Assim, ele percebeu como os professores daquele programa de formação compreendiam o que o formador lhes explicava de forma diferente do esperado, e concluiu que "era 
necessário chegar mais próximo da vivência dos professores” (MALDANER, 2006, p. 199). A estrutura conceitual do formador (a partir da qual ele fala) é inicialmente diferente daquela dos professores (com a qual eles interpretam as falas). A linguagem do formador é especializada e ele a usa para invocar determinados conceitos que estão bem relacionados a uma série de outros e também a uma classe de situações empíricas, dentro dos seus esquemas mentais. $\mathrm{O}$ cuidado com a linguagem é o cuidado com o conceito em construção, pois a relação a ser feita por quem aprende deve ser biunívoca.

O monitor FE, que é um participante veterano do programa que acompanhamos, relatou-nos em uma entrevista, que nos primeiros anos de funcionamento desse programa havia aulas teóricas sobre o construtivismo e as metodologias associadas. E os formadores perceberam que os professores adquiriam esse discurso e procuravam justificar e interpretar - mais do que analisar e modificar - suas práticas por ele. A capacidade de discurso tornava-se mais forte que a tradução desse discurso em uma prática, o que constituía obstáculo para a modificação da atuação docente.

Então, ainda conforme o relato de FE, o que se passou a fazer? Em vez de falar aos professores como deve ser, de forma genérica e ampla, trabalhar com as ideias dos alunos, ou ouvir os alunos, ou conduzir uma aula de forma "construtivista", o formador passou a realizar atividades em que ele trabalhava as ideias dos professores, partindo delas em direção àqueles objetivos de ensino. Da mesma forma, ele os incentivava a buscar informações de como seus alunos compreendiam os conceitos e ou de como modificavam seus argumentos ao analisar os fenômenos. Ele não discorria mais sobre a importância de ouvir os alunos, mas dizia ao professor, "descubra como sen aluno explica esse fenômeno, com o qual você está trabalhando. Descubra a origem do erro dele".

No construtivismo, o ensino parte do que o sujeito tem, do que ele sabe. O formador desse programa foi coerente com essa ideia quando, em vez explicar inicialmente sobre as "concepções prévias", esperou que o professor trouxesse resultados dos alunos para então apontar, "essa ideia, que você perceben que o seu aluno usou para dar essa resposta, é uma concep̧ção prévia."

O professor vivenciava, tanto no programa de formação (como aprendiz), quanto na sua sala de aula (como ensinante), as ideias construtivistas que constituíam um dos objetivos de ensino do formador, mas as teorias pedagógicas foram tratadas como referência e não finalidade, pois as ações do programa focalizavam, de forma mais ampla, a atividade dos professores. Eventualmente algum deles, como VIC, perguntaria - qual a teoria por trás dessa prática? Nesse caso, em que ele já vivenciou um pouco da prática, o diálogo teria maior probabilidade de se dar sob bases comuns.

Para agir dessa forma, percebemos que dois conhecimentos mobilizados pelo formador foram favoráveis:

O conhecimento de física (em termos mais gerais, diríamos o conhecimento da matéria que o professor ensina). A vivência e a observação do professor, e as análises das situações de ensino segundo as ideias construtivistas, eram situadas na prática docente e no problema dos professores de física, que era como ensinar a física. Esse também era o problema tratado no programa de formação, e o construtivismo figurou nele como um dos subsidios para resolvê-lo. Os diálogos se pautaram profundamente sobre o conteúdo curricular da disciplina que os professores lecionavam, de modo que esse auxílio à prática profissional do professor - e esse ensino da teoria construtivista - não seriam possíveis se o formador não tivesse um bom conhecimento de física. 


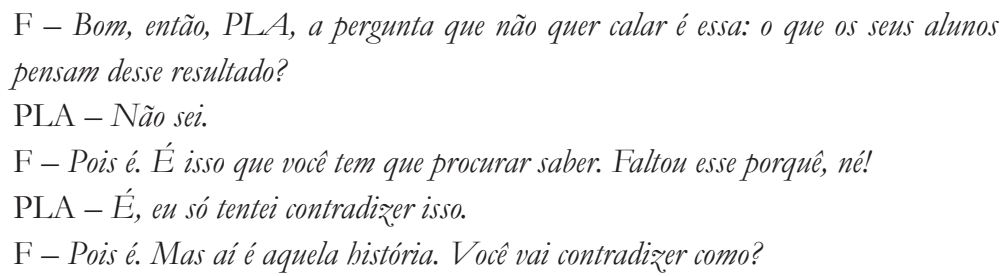

O conhecimento posto em prática da linha pedagógica adotada. O formador, em suas ações com os professores (e não somente no discurso), manteve-se bastante coerente com as concepções de ensino e aprendizagem que ensinava. Dessa forma, o programa conseguia se constituir em um exemplo de ação e uma oportunidade de vivência para o professor, tanto das novas atividades e atitudes de um ensino baseado no diálogo, quanto dos caminhos do aprendizado, seguindo essa concepção em que o aprendiz é ativo no processo. Essa vivência proporcionada ao professor, como aprendiz de um programa "construtivista", trazia maior segurança e poder de previsibilidade quando ele próprio constituísse suas aulas segundo os mesmos princípios.

Notamos, por fim, que o programa não ensinou o a teoria construtivista per se, assim como ela não foi introduzida como uma solução universal para o ensino. O professor também era levado a perceber os limites de utilização da teoria, pois o programa não trabalhou com situações de ensino controladas ou próximas às "ideais". As discussões de avaliação da aprendizagem que reconheciam as condições precárias do trabalho docente, por exemplo, forneciam balizamento necessário e bastante oportuno, mesmo para a própria compreensão do construtivismo.

\section{O exercício da autonomia docente}

A autonomia foi trabalhada pelo programa também a partir da sua estratégia principal de ensino, que era pautar as discussões no planejamento feito pelo professor e em seus relatos de aulas realizadas. A pergunta inicial das reuniões era "Quem deu aula? Conte como foi." - A partir daí, o processo de ensino acontecia.

\section{F - Mas o problema que você deu pra eles, qual foi? Ligar isso tudo e fažer a lâmpada} acender?

TOM - É, isso, por enquanto. Ah, inclusive, teve um grupo que tinha só um fio. Mas foi até proposital, porque eu tinha mais fios guardados, mas pensei, "deixa eu colocar só esse grupinho aqui, pra ver se eles conseguem ou não." Só que eu não falei nada. Ai quando eles começaram a manusear o material, eles falaram, "professora, ah, não dá pra ligar com um fio só." "Tem certeza?" "É, não dá." [...] Ai eu peguei outro fio e dei pra eles, porque eles perceberam que estava faltando, que só no grupo deles tava faltando um fio. Meu intuito era saber se eles iam conseguir acender com um fio só. $\mathrm{Na}$ verdade, não conseguiram.

F - Mas você acha que... será que pra eles foi um desafio?

TOM - Pois é, foi. Pra mim.

F - Porque você fala assim, eles - "ah professora, mas não dá pra acender, só tem um fio." E você, "ah, mas você tem certeza?", e eles dizem "ah, tenho!" Tem certeza do quê, que só tem um fio e os outros têm 2? ... Entende? Porque, nessa situação, você 
vê, ele já olhou o do vizinho... [TOM - olharam, é] Pois é, então, o que você espera que eles fossem considerar? Eles vão pensar, "a professora se enganou”. [...] E por que você quer lançar isso como desafio? Qual a expectativa?

$[\ldots]$

F - Mas como é que/, TOM, eu acho que você... perdeu coisa no meio do caminho. Porque... você acha que eles chegam a essa conclusão com o tempo?

TOM - Não, eles faziam perguntas pra mim.

F - É, pois é, então! Tem uma porção de coisas aí... que não está aparecendo. Porque, do que eu conheço da sala de aula, quando você monta 6, 7 grupos, um olha pro outro. E se um conseguiu acender, os outros vão conseguir. Eu acho que o mais provável é que eles acabem todos acendendo mesmo. [...] Então, pra eles não é um problema complicado, porque eles vão acabar chegando lá e acendendo. Agora, quando que a PLA percebeu, conseguiu detectar alguma dificuldade? Foi quando ela pediu pra fazer o esquema. Porque uma coisa é acender porque viu o outro acender ou porque está acostumado já, ele vê que encosta a lâmpada ali na pilha, isso eles vêem nos aparelhos, né. Agora, outra coisa é ele tomar consciência de que ali tem que ter um circuito, tem que ter algo que entra por um lado e sai pelo outro.

Nesse grupo, como trabalho partia das ações e do plano de ensino do professor a autonomia foi construída a partir daquelas decisões e ações que o professor era capaz de realizar, e o trabalho procurava prover o professor com outras escolhas, e com escolhas mais fundamentadas - como, no episódio exemplificado acima, a análise da aula de TOM desembocaria em novas atividades que a professora poderia desenvolver para proporcionar melhor aprendizado.

As decisões sobre a prática do professor não eram tomadas pelo formador: este não elaborava um plano de ensino a ser aplicado pelo professor, não fornecia "receitas" para resolver os problemas relatados, não decidia a sequência dos conteúdos e não passava nenhuma prescrição de como agir de forma "construtivista" (no episódio ilustrado, TOM relata a aula que ela mesma havia planejado e executado). O professor iniciante no programa, ainda que se supusesse pouco autônomo em suas escolhas pedagógicas, devia elaborar seu próprio plano de ensino, a partir do qual o programa trabalharia.

"Ninguém é autônomo primeiro para depois decidir. A autonomia vai se constituindo na experiência de várias e inúmeras decisões que vão sendo tomadas" (FREIRE, 1996, p. 121). Os problemas abordados nas reuniões de formação adquiriam significação real - porque os problemas eram reais e as hipóteses de soluções (que não seriam técnicas, pois se referiam à complexidade da prática) seriam testadas e os resultados trazidos ao grupo para análise. A análise também não seria feita por alguém externo, pois era o próprio professor que que refletiria, analisaria, buscaria novas soluções.

As discussões se contextualizavam na prática docente real, porém fundamentadas em pressupostos pedagógicos, epistemológicos e didáticos, com os quais os professores começavam a se familiarizar e que começavam também a utilizar para pensar a sua prática - de forma cada vez mais autônoma.

Isso nos leva a reflexões adicionais sobre o foco do programa no processo de planejamento do professor. Essa ideia não é tão recente. Pacca (1992) refletia que nos cursos de atualização profissional em geral, o que comumente é feito é levar ao professor um conjunto de 
ideias e atividades, e ensiná-lo, para que ele as carregue para sua sala de aula. Nessas situações, o professor "constrói muito pouco, não produz quase nada de significativo, não exerce sua função de preparador, organizador, decisor de um programa de ensino" (PACCA, 1992, p. 41). Dessa forma, o próprio curso coloca o professor em uma posição passiva e dependente, de espera por soluções externas.

Em contrapartida, o processo de planejar uma sequência de ensino deslocou o centro de gravidade das decisões e ações docentes, do formador para o professor. No planejamento, o professor mobilizava seus conhecimentos do conteúdo de física, conhecimentos pedagógicos, conhecimentos curriculares e conhecimentos experienciais; o planejamento era um processo genuíno de produção, que aliava saberes acadêmicos e técnicos a saberes próprios da prática, combinados com originalidade e criatividade, mas também coerentes com o objetivo que se queria alcançar.

No episódio que discutiu a aula de TOM, foi apenas porque a própria professora planejou sua aula que a análise dos resultados se fez possível - pois essa análise se baseou nas atividades, nas estratégias e nos resultados alcançados pela professora. Tal análise, entretanto, perderia o valor se o plano de aulas fosse elaborado por outrem - porque o professor não se sentiria responsável por ele e comprometido com o aprendizado esperado.

Vários pesquisadores em Formação Docente defendem a ideia de que os programas de desenvolvimento profissional passem a trabalhar a partir da prática do professor - como já apontamos no início deste texto. O trabalho contextualizado no planejamento do professor é coerente com essa ideia, pois, como afirmou Pacca (1992, p. 41),

Se o programa trabalhar com o professor na elaboração do seu planejamento, ele experimentará a situação de ser ouvido naquilo que é seu problema e de ter suas idéias consideradas e discutidas, para a possível reelaboração. Porque, na realidade, são essas as idéias que ele vai utilizar no enfrentamento dos problemas reais, ao tentar resolvê-los utilizando sua capacidade e competência.

Por outro lado, do ponto de vista do formador, o trabalho com os planos de ensino próprios de cada professor exige uma atuação mais flexivel, e maior capacidade de improviso e de adequação dos objetivos do programa a situações individuais.

Elaborar um plano comum, que todos os professores devem aplicar, certamente simplificaria o trabalho do formador, pois criaria uma maior homogeneidade nas discussões e nos conteúdos a serem ensinados pelo programa. Contudo, não parece ser uma boa alternativa, não somente porque suprime a autonomia do professor em lugar de construí-la, como nossos referenciais defendem, mas também porque planos de ensino são elaborados para uma determinada interação entre o professor e os seus alunos, no atendimento de objetivos específicos que usarão atividades, atitudes, estratégias de ensino que dependerão de vários fatores, inclusive o da subjetividade de cada ator, ou seja, das capacidades e talentos individuais de cada docente. Por mais detalhado que seja um plano de ensino, nunca haverá dois professores que o realizem da mesma forma.

Isso se evidenciou na tentativa dos professores do grupo em aplicar o plano de ensino elaborado no projeto São Paulo Faz Escola. Eles estavam genuinamente tentando fazer o material funcionar, mas, como aponta CLO na discussão a seguir, o plano os deixou mais confusos do que auxiliou de fato as suas aulas: 
$\mathrm{CLO}$ - Eu acho que realmente não estou muito inspirada pra dar aula, mas eu estou tentando. Eu acho que alguma coisa tem que dar certo, sabe? Então, eu vou falar a verdade pra vocês, eu estou entrando na sala de aula, eu não sei se eu estou fazendo certo, mas eu estou tentando, pensando que todos os meus colegas, com algumas excecõos, estão realmente tentando, porque a gente está [trabalhando] com um problema, que existe na educação [que é o baixo aprendizado dos alunos], e eu acho que é mais uma tentativa, sabe? Então, eu realmente vou ser sincera, eu estou fazendo com muita garra, com muita vontade...

$\mathrm{F}-$ Pra dar certo.

CLO - [...] Então/ mas eu estou com dificuldade por quêe? Porque eu estou lendo as aulas, estou vendo direitinho, e eu demoro um tempo pra descobrir qual é o meu objetivo naquela aula-

$\mathrm{ADI}-A$, porque não foi você que escreven!

CLO - Não fui eu, entendeu? Não fui eu [que planejei]. Então, eu estou tentando perceber qual é a minha dificuldade. Aqui [no programa] eu aprendi a ter muito claro pra mim qual o objetivo do meu curso, onde en queria chegar; né, $K A P$, nós duas... [...] Só que agora eu estou tentando me organizar, ver direitinho o que eu quero com eles, qual o meu objetivo, mas não está muito claro pra mim, sabe? Então chega no meio da aula, eu me perco [...]. Então, o que eu percebo comigo, é isso - nãa está claro pra mim o objetivo de cada aula. Eu não senti ainda. Por mais que eu esteja tentando, lendo, percebendo, não está claro pra mim.

Os professores podem realmente, como disse CLO, se esforçar para utilizar um plano de aulas pronto, mas os problemas surgidos parecem ser maiores que os ganhos - eles se sentem confusos, perdem a segurança sobre suas ações durante as aulas e, se de início querem acreditar que o material possa funcionar para a melhora do ensino, acabam frustrados e desanimados com sua própria atuação, como nos mostra a queixa de SIL, ao final de um ano de trabalho com o material fornecido pelo Estado.

SIL - Eu estou pensando em parar de dar aulas. Porque a escola me obriga a usar
esse material, e todos os professores estão usando, porque é mais fácil, não tem mais que
planejar, não tem mais que preparar prova nem nada, é só seguir a apostila. Mas os
alunos estão desanimados, e eu estou desanimada. [...] E se pelo menos eles estivessem
aprendendo física, mas não estão. Se eu pudesse dar as minhas aulas do meu jeito, eles iam
gostar mais e aprender mais - aprender física mesmo, não só aquelas coisas da apostila.

Esses depoimentos são interessantes porque mostram que o professor se identifica com o seu plano de ensino, quando ele o elabora, mas não consegue identificar os objetivos de ensino, nem a relevância do conteúdo, nem a forma de se locomover em uma aula, em um plano feito por outrem - que nos sugere fortemente (conforme já observado desde os grandes projetos da década de 1960) que tentativas de simplificar o trabalho docente - para que eles só "apliquem" algo que outra pessoa, mais sábia e competente, produziu - podem se tornar complicadores.

Favorecer a autonomia docente é imprescindível para um bom trabalho educativo. Exige maior trabalho por parte do formador, maior conhecimento, mais experiência com contextos educativos reais, mais flexibilidade do seu próprio plano de ensino; mas não vemos alternativa producente. 


\section{Conclusões}

O programa que acompanhamos utilizou, como estratégia principal de ensino da prática reflexiva, o diálogo a partir de relatos de aula produzidos pelo professor. Essa estratégia mostrou-se bastante eficiente para que a reflexão fosse desenvolvida pelo grupo de professores, pois colocou todos diante de problemas reais a serem resolvidos, com a segurança de um membro mais experiente conduzindo as reflexões.

O processo reflexivo acontecia a partir da problematização de resultados de aprendizagem, de comportamentos dos alunos, de incômodos subjacentes aos relatos dos professores ou de aulas que não atingiam o resultado esperado. Os processos reflexivos realizados oralmente e em grupo eram eventualmente requeridos na forma escrita, individual e sistematizada, de forma que os participantes do programa podiam perceber que havia uma evolução no desenvolvimento dessa competência.

A reflexão sobre a ação acontecia de acordo com certas balizas, e uma delas era a concepção de ensino em pauta. As análises das situações de ensino e das propostas de planos de aulas se davam embasadas em ideias construtivistas, como o diálogo, o respeito pelo pensamento do aprendiz, a necessidade de colocar o aprendiz como protagonista do processo e o acompanhamento contínuo do processo de construção do conhecimento, com replanejamentos periódicos baseados naqueles feedbacks. Dessa forma, o aprendizado de uma concepção de ensino aconteceu através das ações docentes e da reflexão sobre essas ações.

O protagonista no programa de formação era o professor, que trazia para o programa o seu plano de ensino, os relatos das suas aulas, as suas dificuldades e conquistas. A reafirmação constante da autonomia docente nas reuniões do programa foi um elemento necessário para que as reflexões pudessem acontecer. Apenas porque houve autonomia é que as discussões acerca dos resultados de aprendizagem eram significativas, e apenas porque havia escolha, mas também compromisso e ética profissional, os professores se interessavam sobremaneira em desenvolver atitudes construtivistas.

Dessa forma, pudemos perceber que os três objetivos gerais estavam intimamente conectados e eram trabalhados de forma transversal a todas as ações de formação.

Mais do que isso, nossa análise aponta para um fator muito importante que propicia o trabalho com os objetivos gerais de formação: a competência profissional, o compromisso com a comunidade e a ética, elementos que, segundo Contreras (2002), integram a autonomia docente e figuram como pressupostos ao trabalho do formador.

O que significa, afinal, ouvir o professor e trabalhar a partir de sua prática? Em que essa "escuta qualificada" do formador é uma habilidade profissional, diferente da escuta cotidiana? Antes de tudo, implica assumir uma disposição inicial de acreditar que o professor tem uma competência para o que faz; portanto, começa por uma atitude de profundo respeito àquele profissional que está participando do programa de formação. Em seguida, ao ouvir um relato, buscar os determinantes implícitos daquela prática - que não serão apenas racionais: são também emocionais, ideológicos, paradigmáticos. Para compreendê-los, é necessária uma escuta interessada e completa, por alguém experiente e conhecedor da área, além de disposto a auxiliar o professor no que ele precisa para concretizar suas intenções. Também é oportuno conhecer a pessoa do professor. Segundo a expressão de Patto (1990, p. 352), o formador “[...] deve estar capacitado para uma escuta que, criticamente informada, leve em conta as fantasias, angústias e defesas que acompanham qualquer processo de mudança”. 
Ouvir o professor e partir da sua prática docente é também criar um compromisso com suas aulas, com os problemas que surgem e as novidades encontradas. É também comprometer-se com seu desenvolvimento profissional. Comprometer é um pouco mais que prometer - exige a promessa das duas partes; nem o professor está sozinho, nem o formador é detentor de toda ação.

\section{Considerações adicionais}

Acompanhar a aprendizagem individual torna-se complicado em turmas numerosas. Nesse programa de formação, se o formador tivesse que acolher 50 professores em vez de uma dúzia, um trabalho dessa forma, acompanhando os planejamentos individuais, as angústias que surgiam na prática de cada um enquanto tentava operar mudanças e as ideias novas que precisavam de ajuda para serem operacionalizadas, não seria viável ou, ao menos, não produziriam resultados tão brilhantes.

Então, deparamo-nos com uma questão bastante nevrálgica da educação, que é o problema da quantidade: como proporcionar um programa de formação continuada aos 224 mil professores ${ }^{2}$, considerando-se apenas a rede pública estadual de São Paulo? Que tipo de política pública poderia ser adequada, com base nos resultados dessa pesquisa, para atender aos "223.990 demais professores", que este programa não atingiu?

Consideremos, para responder a essa questão, a seguinte constatação: percebemos que o formador, nesse programa, muitas vezes assumiu funções que seriam pertinentes a uma coordenação pedagógica. Discutir avaliação, tratar problemas de disciplina, analisar a ausência de aulas e as faltas dos alunos, todos esses temas poderiam perfeitamente constar de uma pauta de reuniões na escola, com a equipe escolar e o auxílio de um elemento mais experiente participante do contexto escolar. As soluções e os encaminhamentos para tais questões poderiam inclusive ser mais produtivos se toda a equipe escolar agisse de forma mais coesa.

A figura do coordenador pedagógico existe no Estado de São Paulo desde 1993. No entanto, com os professores desse grupo que acompanhamos, a coordenação pedagógica de suas escolas aparentemente não assumia essas funções. Os professores traziam seus problemas ao formador no programa, e essa parecia ser a única ocasião em que tais problemas poderiam ser discutidos.

Para outras questões, mais específicas da matéria de ensino, poderia ser invocada a figura de um coordenador de área. Em São Paulo, essa figura também existe: há um coordenador para cada área de conhecimento (física, biologia, etc.), por diretoria de ensino (uma diretoria de ensino é um órgão gestor que congrega as escolas de uma determinada região ou cidade). No entanto, o coordenador de área pode requerer reuniões com o professor até quatro vezes durante o ano letivo (apenas quatro!) - em todas elas, retirando o professor da classe. Ou seja,

\footnotetext{
${ }^{2}$ Dados de 2015, para os professores de todas as disciplinas da rede estadual de São Paulo. Disponível em: <http://www1.folha.uol.com.br/educacao/2015/11/1707366-rede-estadual-de-sp-enfrenta-saida-recorde-deprofessores.shtml>. Acesso em: 17 nov. 2015.
} 
para realizar atividades de planejamento pedagógico e desenvolvimento profissional, o professor deve faltar às aulas, agravando o problema das faltas de professores nas escolas.

Por outro lado, os professores têm duas a três horas-aula semanais destinadas ao trabalho pedagógico com a equipe pedagógica da escola (Aula de Trabalho Pedagógico Coletivo - ATPC). É bem pouco, comparado às seis horas semanais de trabalho deste grupo (contabilizando-se somente as horas presenciais). Mas, independente disso, o que é feito nesse período? Como o coordenador pedagógico utiliza os horários de ATPC para discutir o trabalho do professor e os problemas que ele enfrenta, os dilemas e inseguranças que aparecem na sua prática docente?

Porque essa seria uma forma bastante viável de resolver aquele problema da quantidade. O coordenador pedagógico já conhece o contexto de trabalho do professor, está presente diariamente para atender às necessidades que o professor enfrenta e pode atuar de forma tanto individual quanto coletiva, com a equipe docente, na reflexão sobre os problemas concretos que surgem na prática educativa.

Entretanto, alguns relatos do grupo analisado, sobre as ações de coordenadores pedagógicos, nos levam a inferir que pode estar havendo um sério desvio de função desses profissionais na escola. Soubemos de coordenadores que se comportam como "bedéis" dos professores, outros que funcionam como professores substitutos e outros ainda que fazem o papel de inspetores de alunos. Ouvimos de coordenadores que usam o horário de ATPC para convidar os professores a, literalmente, rezar, pela melhoria da sociedade. Outros que dificultam tanto quanto possível a participação do professor em programas como este que acompanhamos.

Desconfiamos fortemente que o coordenador não sabe auxiliar o professor - ou, ao menos, para as cerca de 15 escolas com as quais tivemos contato indireto, através dos participantes do programa, em 13 delas a figura do coordenador escolar esteve absolutamente ausente dos assuntos pertinentes à prática educativa e seus problemas; em apenas duas tivemos indícios, embora bastante tímidos, de alguma participação do coordenador no auxílio aos professores. A atuação do coordenador, nessas duas exceções, contudo, não foi descrita como um diálogo a respeito dos problemas e necessidades docentes, mas apenas como um auxílio, presente porque requerido pelo professor, para a viabilização de alguma atividade.

Onde está o problema? Nossa pesquisa não nos permite responder a essa questão especificamente, no entanto vemos claramente que é necessário o tratamento de toda a escola, quando se deseja melhorar as práticas educativas e a aprendizagem dos alunos.

O que podemos com maior certeza afirmar é que o acompanhamento pessoal ao professor e às equipes escolares, de forma mais constante, é imprescindível para o bom andamento do ensino. Como está nos parecendo que esse acompanhamento inexiste não apenas por problemas estruturais e burocráticos, forçamo-nos a concluir que é preciso também formar formadores de professores - ensinar aqueles que mantêm contato regular com os professores a efetivamente auxiliá-los em sua prática docente.

Realizar um programa de formação de professores é de fato muito diferente de realizar um treinamento ou capacitação. Não se trata apenas de uma atualização dos termos. A formação contínua e as ações que propiciam um desenvolvimento profissional mais holístico requerem a participação de um aprendiz que já é atuante e responsável em seu trabalho, e que está em constante desenvolvimento.

Não se faz formação de massas. Podemos fazer treinamento para as massas. Mas um professor bem "treinado" não é exatamente o que queremos, para melhorar a educação brasileira. Vemos que é necessário um profissional flexível, que saiba trabalhar as diferenças, avaliar planos 
Objetivos gerais de um programa de desenvolvimento ...

de ensino, adequar atividades e educar para a cidadania. Também queremos professores talentosos e criativos e que saibam escolher, no seu acervo pedagógico, os melhores elementos para trabalhar com a diversidade de situações concretas que encontram em sua prática. Estas todas são qualidades não-técnicas, portanto treinamentos não funcionam para ensiná-las. Precisamos de uma formação de fato. Ainda que para isso tenhamos que começar por uma formação para formadores.

\section{Agradecimentos}

O apoio do Conselho Nacional de Desenvolvimento Científico e Tecnológico (CNPq).

\section{Referências}

ALARCÃO, I. (Org.). Formação reflexiva de professores: estratégias de supervisão. Porto: Porto Editora, 1996.

CONTRERAS, J. A autonomia de professores. São Paulo: Cortez, 2002.

FREIRE, P. Pedagogia da autonomia: saberes necessários à prática educativa. São Paulo: Paz e Terra, 1996.

LYONS, T. Different countries, same science classes: students' experiences of school science in their own words. International Journal of Science Education, Abingdon, v. 28, n. 6, p. 591-613, 2006.

MALDANER, O. A. A formação inicial e continuada de professores de química. Ijuí: Editora Unijuí, 2006.

MINAYO, M. C. S. (Org.). Pesquisa social: teoria, método e criatividade. 29. ed. Petrópolis: Vozes, 2010.

NÓVOA, A. Profissão professor. Porto: Porto Editora, 1995.

PACCA, J. L. A. O profissional da educação e o significado do planejamento escolar: problemas dos programas de atualização. Revista Brasileira de Ensino de Física, São Paulo, v. 14, n. 1, p. 39- 44, 1992.

PATTO, M. H. S. A produção do fracasso escolar: histórias de submissão e rebeldia. São Paulo: T. A. Queiroz, 1990.

PERRENOUD, P. Práticas pedagógicas, profissão docente e formação: perspectivas sociológicas. Lisboa: Nova Enciclopédia, 1993.

PIMENTA, S. G. Professor reflexivo: construindo uma crítica. In: PIMENTA, S. G.; GHEDIN, E. (Org.). Professor reflexivo no Brasil: gênese e crítica de um conceito. São Paulo: Cortez, 2002. p. 17-52. 
Scarinci, A. L.; Pacca, J. L. A.

PIMENTA, S. G.; GHEDIN, E. (Org.). Professor reflexivo no Brasil: gênese e crítica de um conceito. São Paulo: Cortez, 2002.

SCARINCI, A. L. Uma proposta para caracterizar a atuação do professor na sala de aula. 2006. 158 f. Dissertação (Mestrado em Ensino de Ciências) -Universidade de São Paulo, São Paulo, 2006.

. Tirando o coelho da cartola: a atuação do formador em um programa de desenvolvimento profissional docente. 2010. 230 f. Tese (Doutorado em Educação) Faculdade de Educação, Universidade de São Paulo, São Paulo, 2010.

SCARINCI, A. L.; PACCA, J. L. A. O truncamento da sequência pedagógica do professor de física. Investigações em Ensino de Ciências, Porto Alegre, v. 18, n. 3, p. 681-696, 2013. Disponível em: <https://www.if.ufrgs.br/cref/ojs/index.php/ienci/article/view/120/84> . Acesso em: 29 set. 2016.

SCHÖN, D. Educando o profissional reflexivo: um novo design para o ensino e a aprendizagem. Porto Alegre: Artmed, 2000.

SOUZA, I. F. Autonomia de professores e formação continuada: perspectivas de integração universidade e escola. 2004. 214 f. Dissertação (Mestrado em Ensino e Aprendizagem) - Universidade de São Paulo, São Paulo, 2004.

STENHOUSE, L. Investigación y desarrollo del curriculum. Madrid: Morata, 1984.

VIEIRA, F. Alunos autônomos e professores reflexivos. In: TAVARES, J.; ALARCÃO, I. (Org.). Para intervir em educação: contributos dos Colóquios CIDInE. Aveiro: Ed. CIDInE, 1994. p. 331-339.

VILLANI, A.; PACCA, J. L. A. Un curso de actualización y cambios conceptuales en professores de física. Enseñanza de las Ciencias, Barcelona, v. 14, n. 1, p. 25-33, 1996.

ZEICHNER, K. M. El maestro como profesional reflexivo. Cuadernos de Pedagogia, Madrid, n. 220, p. 44-49, 1992.

Artigo recebido em 25/09/2015. Aceito em 12/04/2016.

Endereço para contato: Universidade de São Paulo (USP), IF-DFAP, Rua do Matão, tv. R, 187, Cidade Universitária, Ed. Principal, Ala 2, s. 325, CEP 05314-970, São Paulo, SP, Brasil. 